\title{
The forgotten forest: Revisiting the Forestland Allocation Strategy
}

\author{
by Erin E. Sherry ${ }^{1}$ and Chris J. Johnson ${ }^{2}$
}

That British Columbia's forest industry faces severe environmental, social, and economic problems can be denied by only the most optimistic of forest managers. There is a crisis in our woods and people are looking for permanent solutions. Big, bold ideas are required to guide us out of the morass, including new approaches for allocating forestlands among different uses. Binkley's forestland allocation strategy (FAS) is one such proposal. This scheme, although efficient from an economic perspective, is seriously flawed from an ecological and aboriginal standpoint. These shortcomings render the FAS infeasible.

Key words: forest management, forest policy, British Columbia, forestland allocation strategy, wildlife, First Nations

\section{Introduction}

The environmental, social, and economic challenges facing BC's forests must be confronted; but, is Binkley's (1997) alternative, zoning the forest into a series of special use areas, the answer? The forestland allocation strategy (FAS) proposes to divide the forest, according to an array of societal values, into three general zones: intensive timber production areas, strictly protected areas, and integrated management joint use areas. This strategy includes designation of specific land use areas for specific users; clear management rules appropriate to the values provided on each zone; and effective institutional arrangements that furnish appropriate management incentives. Parks and preserves would be managed to sustain their unique ecological values, some cases involving no more than custodial management and others requiring intentional intervention to alter ecosystem trajectories. Management of joint use areas would be responsive to environmental needs and nominally occur through the Forest Practices Code. Timber production areas would be managed intensively. A relaxed set of forest practice standards would govern intensive timber management, minimizing regulations and policy-driven constraints.

By substituting the productive factors of capital, labour, and knowledge for land, the FAS aims to produce a range of desired outcomes, from timber production to environmental preservation. The FAS is based on three key assumptions.

\section{Increases in fibre production on intensively managed areas will more than offset productive losses in protected and joint use areas. A "hypothetical but realistic representation}

\footnotetext{
${ }^{1}$ University of Northern British Columbia, Faculty of Natural Resources and Environmental Studies, Forestry Program, 333 University Way, Prince George, BC V2N 4Z9.E-mail: eesdjs@netbistro.com

${ }^{2}$ University of Northern British Columbia, Faculty of Natural Resources and Environmental Studies, Forestry Program, 333 University Way, Prince George, BC V2N 4Z9. E-mail: johnsoch@unbc.ca
}

Le fait que l'industrie forestière de la Colombie-Britannique fait face à de sérieux problèmes environnementaux, sociaux et économiques ne peut être nié que par les plus optimistes des gestionnaires forestiers. Une crise fait rage dans nos forêts et les gens sont à la recherche de solutions permanentes. Il nous faut de grandes et audacieuses idées pour nous guider hors de ce marasme, en plus de nouvelles approches au niveau de l'allocation des terres forestières entre les différentes utilisations. La stratégie d'allocation des terres de Binkley (FAS) représente l'une de ces possibilités. Ce schéma, même s'il est efficace en terme économique, est sérieusement handicapé au point de vue écologique et autochtone. Ces trous rendent le FAS irréalisable.

Mots-clés: aménagement forestier, politique forestière, Colombie-Britannique, stratégie d'allocation du territoire forestier, faune, Premières Nations

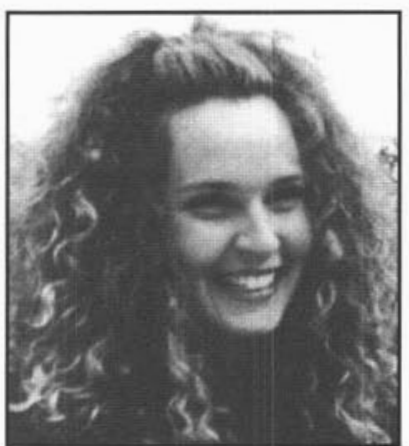

Erin Sherry

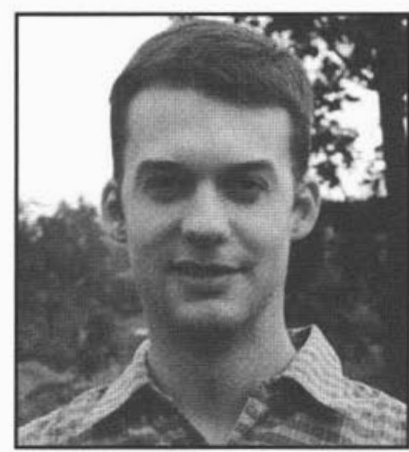

Chris Johnson of the possibilities" for increasing BC's harvests on a reduced land base is contained in the FAS (Binkley 1997). Implementation would require that 17 million ha of productive forest be dedicated to intensive timber management. The FAS assumes that intensification of silviculture research and capital investment will be adequate to increase per-hectare yields two- to three-fold over unmanaged natural stands, producing a timber harvest of 100 million $\mathrm{m}^{3}$ year $^{-1}$ (i.e., $40 \%$ greater than the current AAC).

2. The FAS will be more effective in achieving provincial objectives for the conservation and use of wildlife than current forest management models. This assumption relies on the designation of a core of strictly protected areas, which represent the variety of $\mathrm{BC}$ ecosystems. Intended to support the environmental values of BC's forests, these protected areas would encompass $75 \%$ of the province: 30 million ha of productive forest, 20 million ha of savannahs and other vegetated land, and 20 million ha of "rocks and ice" (Binkley 1997). 


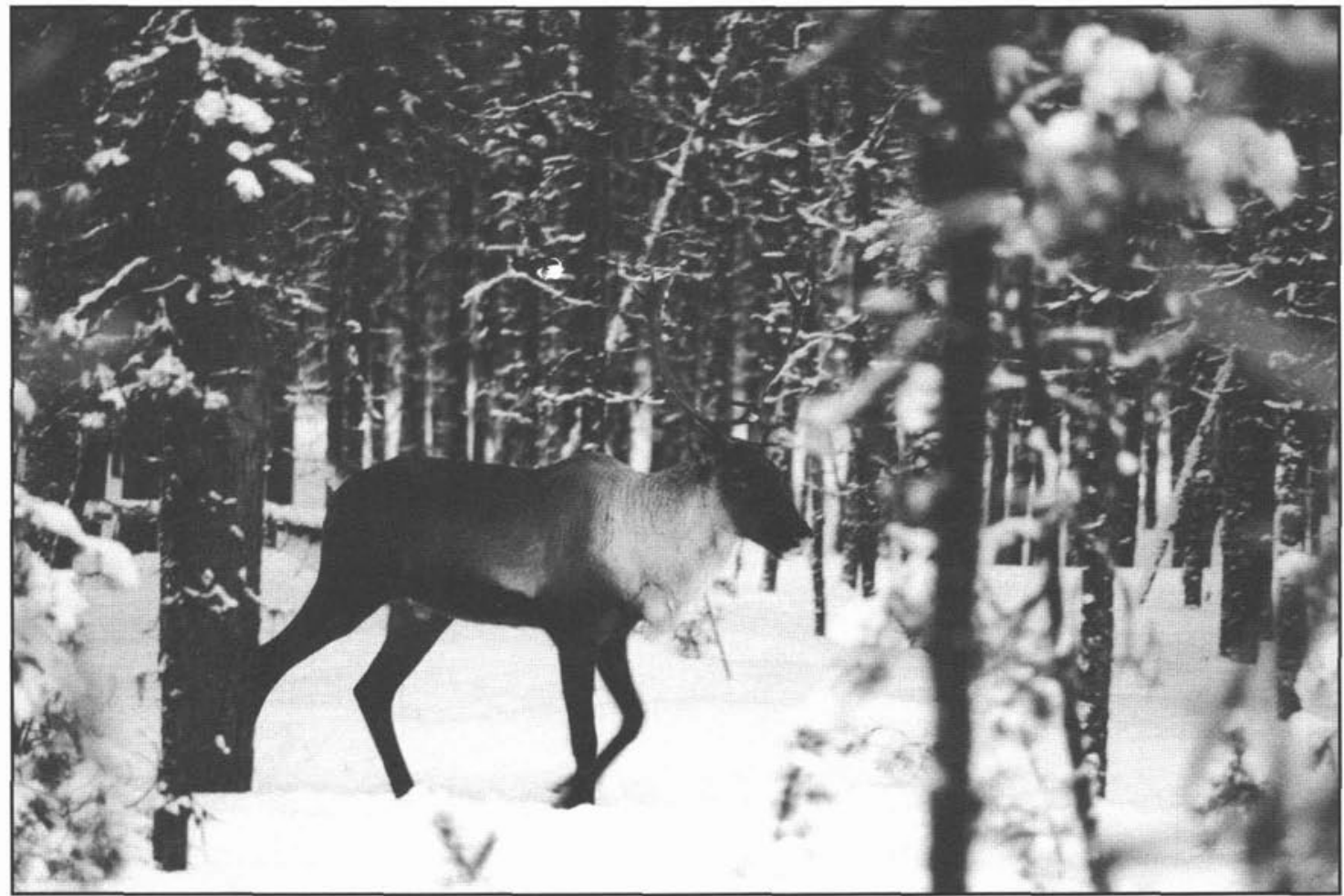

Fig. 1. Forest harvesting and silvicultural practices conducted with concern for the specific habitat requirements of species such as woodland caribou are critical to the conservation of late seral stage associated or dependant species. Under the FAS, reduction in the complexity and diversity of forestlands will result in the exclusion or loss of species.

\section{The FAS will be more socially acceptable than the status} quo. Currently, forest management is mired in regulations, uncertainty, and social unrest. It is assumed the FAS will have a settling effect on these debates.

Is the FAS a viable solution for BC's troubled forests or a Pandora's box which, once opened, will release a new set of problems? In analyzing the forestland allocation strategy, we hope to offer fresh perspectives on its pitfalls and potentials. We do not address the complex economic and technical silviculture aspects of the FAS - an analysis emphasized in the treatise by Binkley (1997) and better dealt with by others. Instead, we offer perspectives from Wildlife Ecology and First Nations Studies - views of the forest that were mostly forgotten by the FAS. Our purpose is to demonstrate that assumptions 2 and 3 of the FAS are seriously flawed. Although increasing the efficiency and profitability of BC's forest industry, while protecting non-timber forest values is an alluring goal, the FAS refuses systematic application. We argue that, without practical respect for and thoughtful consideration of ecological and aboriginal issues, any proposed remedy to the crisis in our woods is untenable.

\section{Thoughts of a Wildlife Ecologist}

British Columbians expect their forests to provide both jobs and tax revenue while serving as productive places for a diverse array of plants and animals. However, managing the Province's 92 million hectares to meet those often-conflicting expectations is a complex problem. Years of debate at home and abroad have produced no simple scientific, political or socio-economic formulas. Most recently, the FAS has been proposed as a landmanagement model through which both the needs of industry and wildlife can be met. However, we believe that the temporal and spatial inflexibility of this large-scale zoning approach, in combination with our lack of knowledge about ecological systems and processes, will lead to a reduction in the distribution, abundance, and value of wildlife. We will demonstrate why the FAS is flawed with respect to assumption 2 by pointing out its potentially negative effects on wildlife. Negative effects are anticipated because the FAS neglects landscape level wildlife issues, incorrectly assumes that parks will suffice as ecological preserves, fails to account for decreased integrated resource management (IRM) opportunities, and fails to adequately address the manner in which British Columbians use wildlife.

\section{Intensive Management Areas: A Threat to Diversity and Abundance}

Most ecologists and natural resource managers agree that our knowledge of ecosystem processes is poor; however, based on our understanding of simpler species-habitat relationships, it is clear that the commitment of large contiguous areas of forest to short rotation stands within intensive management zones will result in the exclusion or loss of species (Swanson and Franklin 1992, Tracy and Brussard 1994, MacKinnon 1998). A reduction in the complexity and diversity of forest stands and landscapes will affect a wide range of life forms - from soil arthropods to amphibians, cavity nesting birds to anadromous fish, and large mammals to canopy insects. The Brown Creeper, for example, which builds nests under loose bark requires structural diversity in the form of standlevel features such as standing snags, woody debris, and large diameter trees (Schieck et al. 1995). More complex, largerscale relationships, such as the indirect reliance of woodland 


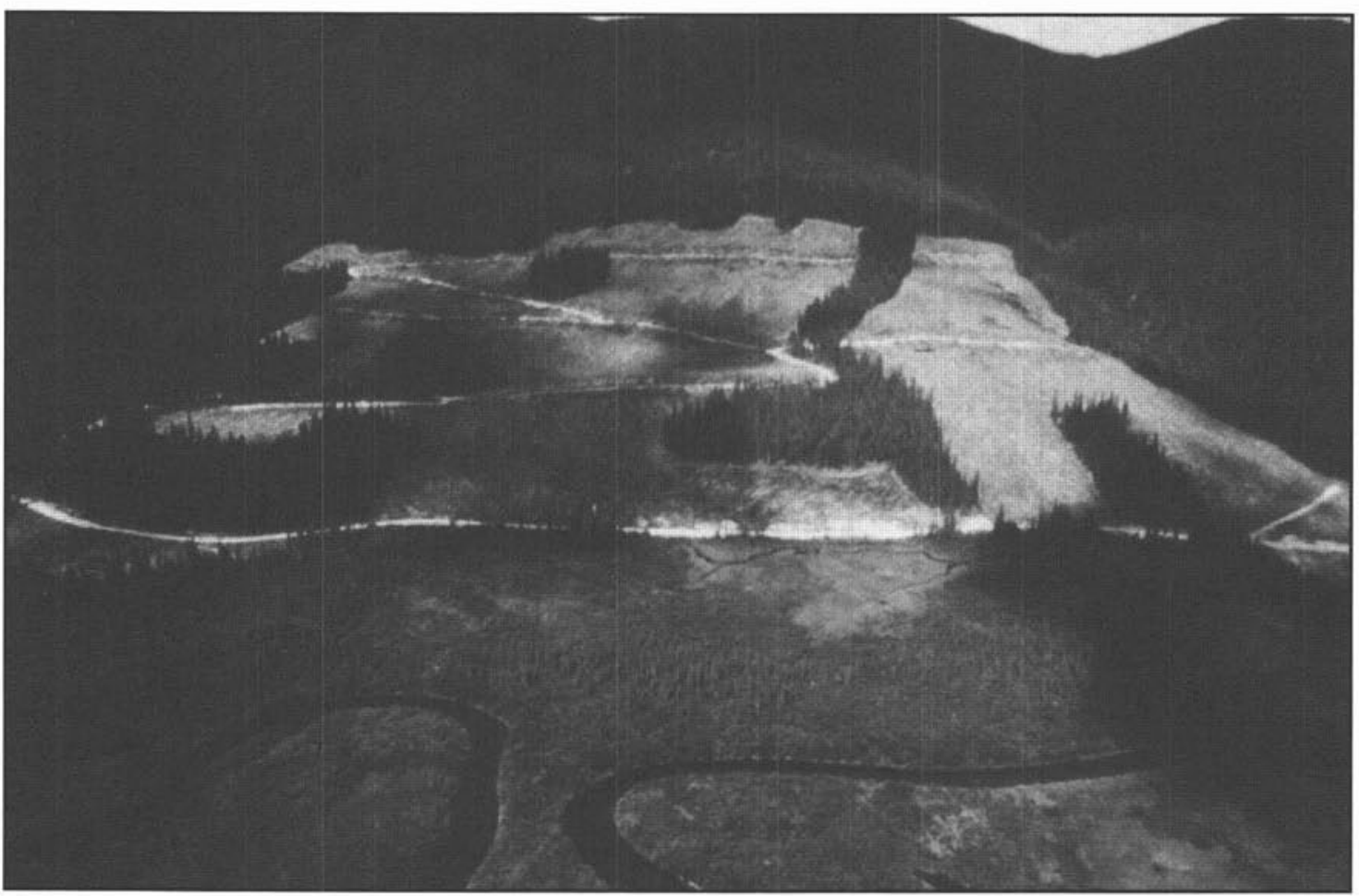

Fig. 2. Current forest management guidelines require the maintenance of wildlife tree patches, riparian buffers, and connectivity corridors. By providing a diversity of stand ages, patch sizes, and stand types these practices will ensure suitable habitat while adjacent harvested areas mature.

caribou on lichen-rich late seral stage stand conditions, need to be managed from an ecosystem perspective, across the landon scape (Seip 1998). However, under the FAS, forest harvesting ป would be conducted with little or no concern for the specific habitat requirements of the wildlife that inhabit the intensive management zone. The conversion of multiple landscapes to homogenous early seral stage forests would disrupt simple to complex ecological interactions and leave little to no habitat for the woodland caribou, Brown Creeper, or a myriad of other late seral stage-associated or dependent species. Even typical early seral stage species, such as moose and blacktailed deer, which use a variety of stand types throughout the year, would be negatively affected by a management regime which simplifies forest age and structure across entire watersheds (Nyberg and Janz 1990, Demarchi and Bunnell 1995).

Some may argue that contemporary forest management has as large or a greater negative effect on wildlife than would be expected under the proposed FAS. While current management does result in a net loss of habitat, there are provisions to retain wildlife tree patches, riparian buffers, and connectivity corridors and to harvest in a way that provides a more natural distribution of stand ages and patch sizes (BC Ministry of Forests 1995). Although the effectiveness of these practices remains unproven, current strategies provide habitat conditions that may sustain late seral stage-dependent species until adjacent stands mature and there is a diversity of patch types for species with a range of habitat requirements (Seip 1998). Ecosystem approaches are criticized; however, relative to the FAS, they have a greater potential to conserve wildlife across the entire province (Simberloff 1998).

\section{Parks: Can We Zone Conservation?}

Implicit within the FAS is the assumption that increasing the number and area of parks will compensate for lost habitat. However, as Binkley (1997) readily admits and others have echoed (Wright 1999), the ability to design and manage ecologically functional parks and reserves is constrained by the state of scientific knowledge. Unknowns such as minimum viable population sizes are difficult to calculate for charismatic animals like the grizzly bear, never mind other less understood species such as the flying squirrel. Insular populations may be affected by demographic, environmental, and genetic stochasticity as well as catastrophic events such as fire, drought, and flooding, all of which are difficult to predict and manage (Soulé and Simberloff 1986, Shafer 1990). Connectivity, reserve size and number, and the mitigation of external land use pressures are other questions that test not only our understanding of ecological relationships, but also managers' ability to perform within the political arena (Wilcove and May 1986, Burkey 1989). Even if we could establish boundaries to meet ecological rather than political objectives, it is unlikely that affected species within intensive management areas would alter migratory pathways or traditional ranges to use the habitats afforded by parks (Newmark 1985).

Under the FAS, a large portion of the province would be set aside to support environmental values. We applaud the creation of protected areas, but for several reasons question the legitimacy of such a plan. First, $55 \%$ of FAS protected areas would consist of savannahs and "rock and ice," portions of the province with no commercial value to the forest industry. These protected areas, selected more for their recreational and scenic values, would contribute minimally to the conservation 


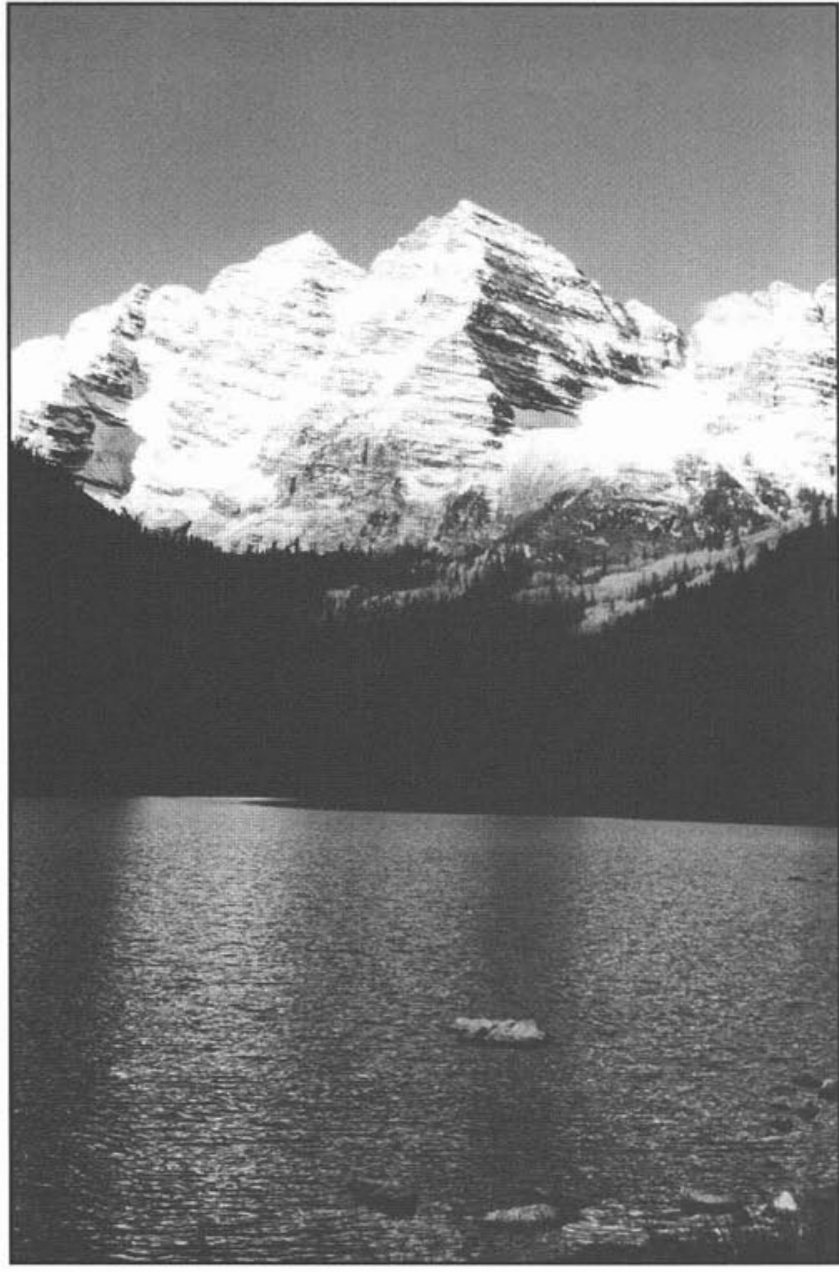

Fig. 3. The 20 million ha of 'rocks and ice' and 20 million ha of savannahs and other vegetated land dedicated to protected areas under the FAS have no commercial value to the forest industry. Intensive forestry will predominate across much of BC's most productive forestlands, reducing the diversity and abundance of wildlife throughout those areas.

of wildlife. The FAS allows the forest industry to claim the best growing sites; consequently, intensive forestry will predominate on BC's most productive forestlands. The FAS parks promise clouds the real issue, dedication of one third of the province's most biologically diverse habitats to nothing more than short rotation "tree crops." Second, the FAS takes no account of other users of forested and non-forested lands. It is unreasonable to assume that other sectors of the economy would forgo development opportunities to accommodate commercial forestry and fulfil the FAS protected area pledge. BC's other resource stakeholders have their own perspective on the percentage and placement of parks, leading us to believe that something less than an area the size of France would be set aside for wildlife and environmental services. Even if a large portion of BC's forests are dedicated to parks, past experiences have shown that ecological processes are inherently complex and that protected areas are just one component of an effective conservation strategy (Huff and Varley 1999). Parks in themselves are not a fail-safe device for "preserving nature."

\section{Do Wildlife Fit Within Integrated Management Joint}

\section{Use Areas?}

Binkley (1997) provides no rationale for the development, placement, and size of integrated management joint use areas. We assume that this zone will accommodate moderate harvesting and existing or future human activities, such as agriculture or mining, that are incompatible with both protected and intensive management areas. In this zone, there is the possibility to integrate several resource objectives; however, carving up the provincial landscape into intensive management zones and protected areas means only a portion of the previous IRM opportunities remain. Because of the need to accommodate a wide range of human activities over relatively small areas, planning and management approaches designed to protect wildlife and their habitats will be constrained. Other sectors of the BC economy, pointing to the extent of protected areas set aside by the FAS, will expect regulatory concessions similar to those granted the forest industry within intensive management zones. Consequently, wildlife will finish behind those human activities heavily concentrated in joint use areas.

\section{Disturbance at the Scale of Landscapes}

Forest harvesting does not simply modify habitat but, depending on the spatial and temporal characteristics of logging, may also lead to a reduction in the connectivity of habitat patches and landscapes (Harrison and Voller 1998). Under the FAS, large areas of homogeneous single-age stands would act to truncate existing ranges and movement corridors, fragmenting wildlife populations and isolating large patches of "nonproductive' forestland that serves as habitat. British Columbia could become a series of disjointed habitat islands, interspersed with intensive management or integrated management zones that prevent or restrict the colonization and use of certain areas of the landscape as well as the transfer of genetic material between populations (Harris 1984). In theory, protected areas could be arranged across the province in a way that would maintain known migratory corridors and facilitate ecological connectivity. In practice, however, our knowledge of animal movements and ecological processes is insufficient to make such decisions with any certainty. We must also consider the economic, social, and political constraints that will dictate the placement of those zones intended for wildlife.

The ability to account for all species at all spatial scales is limited by our understanding of ecological processes and our need to harvest and modify some percentage of the forested land base. The consequences of our actions are difficult to predict, especially at the scale of community and ecosystem interactions, and could take years to manifest as declining populations (Taylor et al. 1993). However, the inherent inflexibility of the FAS - a consequence of private ownership, restricted protective legislation, and large contiguous harvest areas - would restrict our ability to mitigate such effects. Alternatively, current approaches recommended through Forest Practices Code guidelines are spatially and temporally more flexible because they operate at element, stand, landscape, and regional scales. This allows us to work within an "adaptive management" framework whereby harvest objectives and land-use designations can be modified as knowledge of ecological systems and focal populations increases (Walters 1986). 


\section{Disrupting Human Uses of Wildlife}

Evidence suggests that a reduction in the distribution and abundance of wildlife would run counter to British Columbians' values, affecting both their quality of life and livelihoods. In financial terms, $\mathrm{BC}$ residents and visitors alike are willing to spend considerable amounts to harvest, enjoy, and preserve this province's biodiversity. For example, Reid (1990) estimated that between 1988-1989 BC residents and non-residents spent \$144.3 million on hunting activities; residents spent \$611.1 million on non-hunting activities; and residents spent $\$ 9.2$ million on trapping. British Columbians indicated that they would be willing to voluntarily contribute nearly $\$ 131.8$ million to preserve the present abundance and variety of wildlife in the province (Reid 1990). Stone (1988) estimated that in 1985 the net economic value of resident fresh water angling in BC was $\$ 89.1$ million. Relative to the $\$ 710$ million (1992-1993) that the forest industry generates in stumpage, royalties, fees, and taxes, the value of wildlife ( $\$ 985.5$ million) is significant and must not be marginalized when considering the risks inherent within sweeping tenure reforms such as the FAS (BC Ministry of Forests 1994).

Under the FAS, subsistence hunters, trappers, and guideoutfitters could find that the areas they once hunted and trapped no longer support desirable species or that their activities must be relocated to distant, less convenient, and less familiar locations reclassified as joint use areas or parks. The same would hold true for non-consumptive users for whom encountering a range of wildlife is an important component of enjoying our forests. People who expect more from the forest than fibre and timber products may resent or resist the largescale alteration of forest landscapes which force them to abandon traditional or familiar areas.

If, under the FAS, private owners do allow public use of intensive management areas, the experience of outdoors people may be degraded. Their aesthetic and wilderness experiences may be reduced (Reid 1997) or they may perceive intensive forestry practices' negative impacts on species diversity. Big game hunters surveyed in Alberta indicated that forest management should emphasize a variety of plants and animals and the majority considered setting aside forests from logging as more important than providing jobs and economic development (McFarlane et al. 1998). This example illustrates that the acceptance of forest management practices by the public is dependent on the recognition and incorporation of a variety of societal values (Bengston 1994). How will the public, many of whom regularly visit or use forestlands, respond to the relaxation of "minimum rotation ages, green-up/adjacency, and visual quality objectives" and "outright privatization" across $33 \%$ of BC's forested land base (Binkley 1997)?

\section{An Untenable Alternative}

The FAS is a non-adaptive, static approach with little flexibility to modify management objectives or incorporate new ecological knowledge, changing technology, or public values. This is not to say that an adaptive, ecosystem approach to land management is without difficulties nor is it to suggest that commercial forestry is inappropriate and that some form of land zonation is unrealistic. Rather, we argue that 17 million ha is too much forest to dedicate to short rotation plantations over large contiguous areas and that the FAS is too simplistic and inflexible to account for the uncertainty that accompanies the conservation of species and ecosystems. Swanson and Franklin (1992) best summarize our position: “ $\ldots$ there is not now or will there ever be a simple set of prescriptions for multipleuse, multiple-value, management of complex ecosystems."

\section{Thoughts of a Social Scientist}

We have demonstrated that social objectives related to wildlife would be heavily impacted by the FAS and recognize that other forest uses and values (e.g., recreation or aesthetics) could also be compromised. However, this discussion will focus on a major social consideration prominently missing from Binkley's (1997) treatment of the FAS: the needs and rights of BC First Nations.

What we were losing just went on and on. After logging, the companies sprayed the land. The berries were sprayed with we don't know what. It was some type of herbicide. It killed off the alder. The animals lost their habitat and had to go somewhere else. That had a tremendous affect on us in terms of our diet. Not only that, the litter from logging did major damage to the rivers, to beaver dams. A major coho lake was logged to the edge of the lake, destroying the run. The coho are almost extinct. (Kosek 1993)

The words of Nuu-Chah-Nulth Chief Simon Lucas echo the experience of many BC First Nations. Historically, BC forest management was industry-dominated and disavowed aboriginal cultural and subsistence ties to the forest. Today, aboriginal issues are prominently at the forefront of the provincial conscience. It is now widely recognized that British Columbia's first people, far from being interesting relics of the past, are full and equal participants in our society. The FAS overlooks these considerations, continuing a long-standing tradition of exclusion and denial of power by ignoring legitimate claims of BC First Nations to lands, resources, equity, and control. This social issue, more than any other, has the potential to invalidate assumption 3 of the FAS. We reveal the fundamental lack of consideration for aboriginal issues in the FAS by examining its relationship to international forestry obligations, aboriginal rights, land claims, aboriginal forest values, and alternative knowledge and management systems.

\section{An International Perspective}

Canada is a signatory to all major global instruments concerning temperate forestry. These agreements underline the significance of indigenous culture, needs, aspirations, and participation in resource development and management. For instance, the UN Conference on Environment and Development highlighted the importance of forest ecosystems to indigenous peoples through their Guiding Principles on Forests: "National forest policies should recognize and duly support the identity, culture, and rights of indigenous communities. Appropriate conditions should be promoted for these groups to have an economic stake in forest use, perform economic activities, and achieve and maintain cultural identity, social organization, as well as adequate levels of livelihood" (United Nations 1992: Element 5a). As the world's greatest exporter of forest products and pulp, Canada is greatly dependent on forest resources to meet economic and employment needs and, as such, is susceptible to the vagaries of international opinion and political pressure (Bunnell 1996). Our duty to treat indigenous people according to international expectations is as important as the need to be competitive in global markets. This has far-reach- 


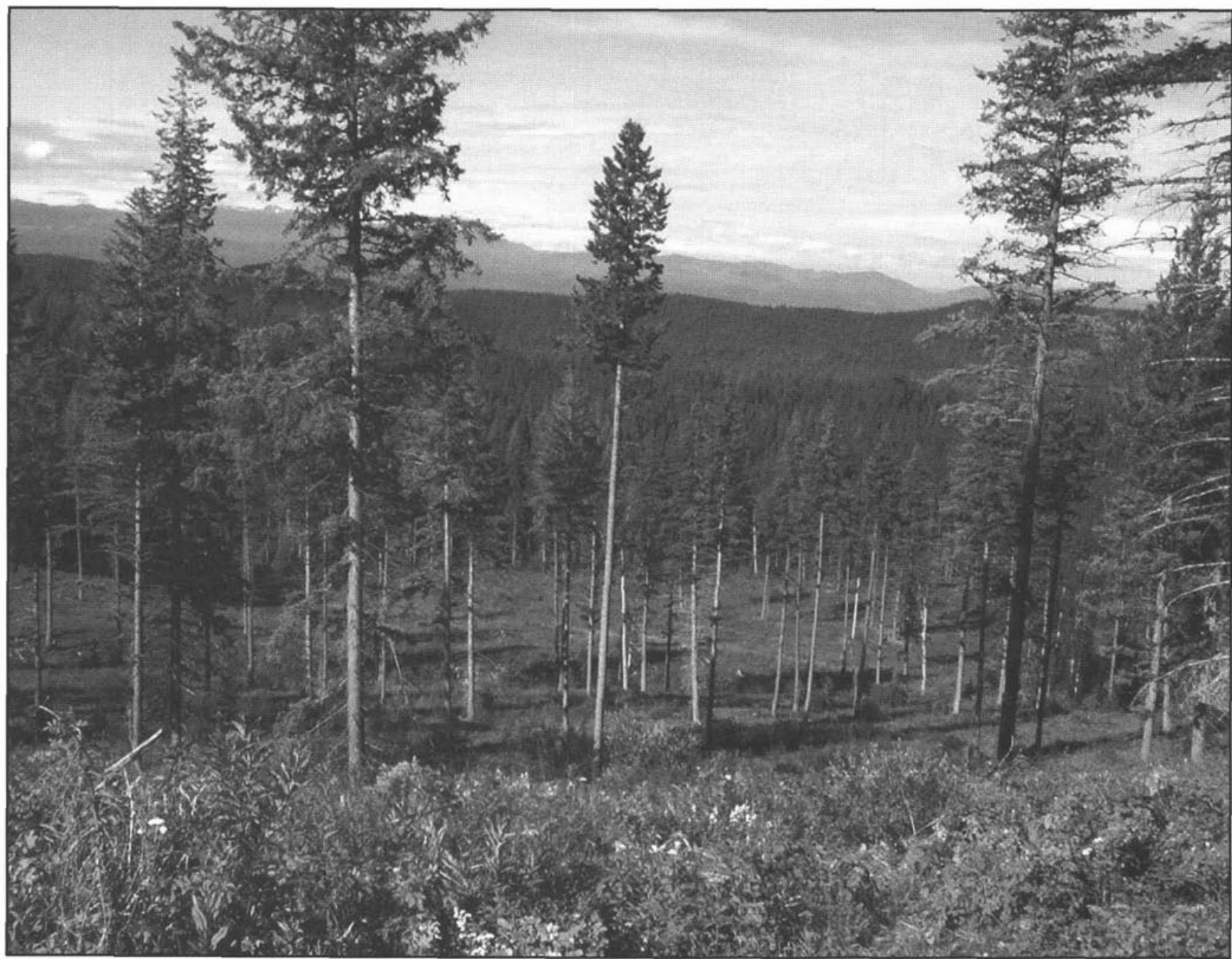

Fig. 4. International agreements on temperate forestry recognize and support the identity, culture, and rights of indigenous communities. The Tl'azt'en First Nation, BC actively participates in forest use, management, and planning as partners with the University of Northern British Columbia in the John Prince Research Forest (as pictured above).

ing implications for any provincial forestland management plan. However, consideration of BC First Nations is conspicuously missing throughout the FAS. If BC is to develop world class approaches to forestry, aboriginal perspectives must be thoughtfully and substantively incorporated.

\section{Closer to Home: Canadian Courts and Provincial Negotiating Tables}

A redefinition of the relationship between aboriginal and non-aboriginal Canadians is resulting in the transformation of power structures and responsibilities concerning natural resources at negotiating tables, in the political arena, out on the land, and in the courts. As the first people of Canada, aboriginal groups claim unique, persistent and unextinguished rights as well as custodial obligations to sustain traditional lands through responsible use. First Nations are not just another forest stakeholder, a competing third party interest, or a special user group. Under Canadian law, aboriginal people are "citizens different," with rights of sovereignty, self-government, and resource use that distinguish them from other Canadians. The FAS completely disregards this newly emerged constitutional and legal relationship. It lacks features to improve and affirm First Nations' rights in BC. The FAS also falls short of realizing the concomitant prospect for new resource management partnerships between aboriginal and non-aboriginal people.

\section{Aboriginal Rights}

In $\mathrm{BC}$, forest management is guided by the results of precedent-setting court rulings such as Calder [1973], Sparrow [1990], Apsassin [1995], and Delgamuukw [1997]. These decisions have prompted widespread change to "business as usual" resource management approaches by beginning to explicitly define aboriginal and treaty rights: establishing that aboriginal title to land is unique; resolving that aboriginal rights to hunt, fish, trap or gather take precedence over alternative land uses; and verifying that aboriginal rights can be exercised in a form that reflects a community's evolution. They confirm that aboriginal rights include involvement in conservation, regulation, and management of resources and dictate that the Crown has trust-like legal and financial obligations to protect aboriginal interests. The Calder, Sparrow, Apsassin, and Delgamuukw rulings make it clear that aboriginal people not only want access to and an equitable share of resources, 


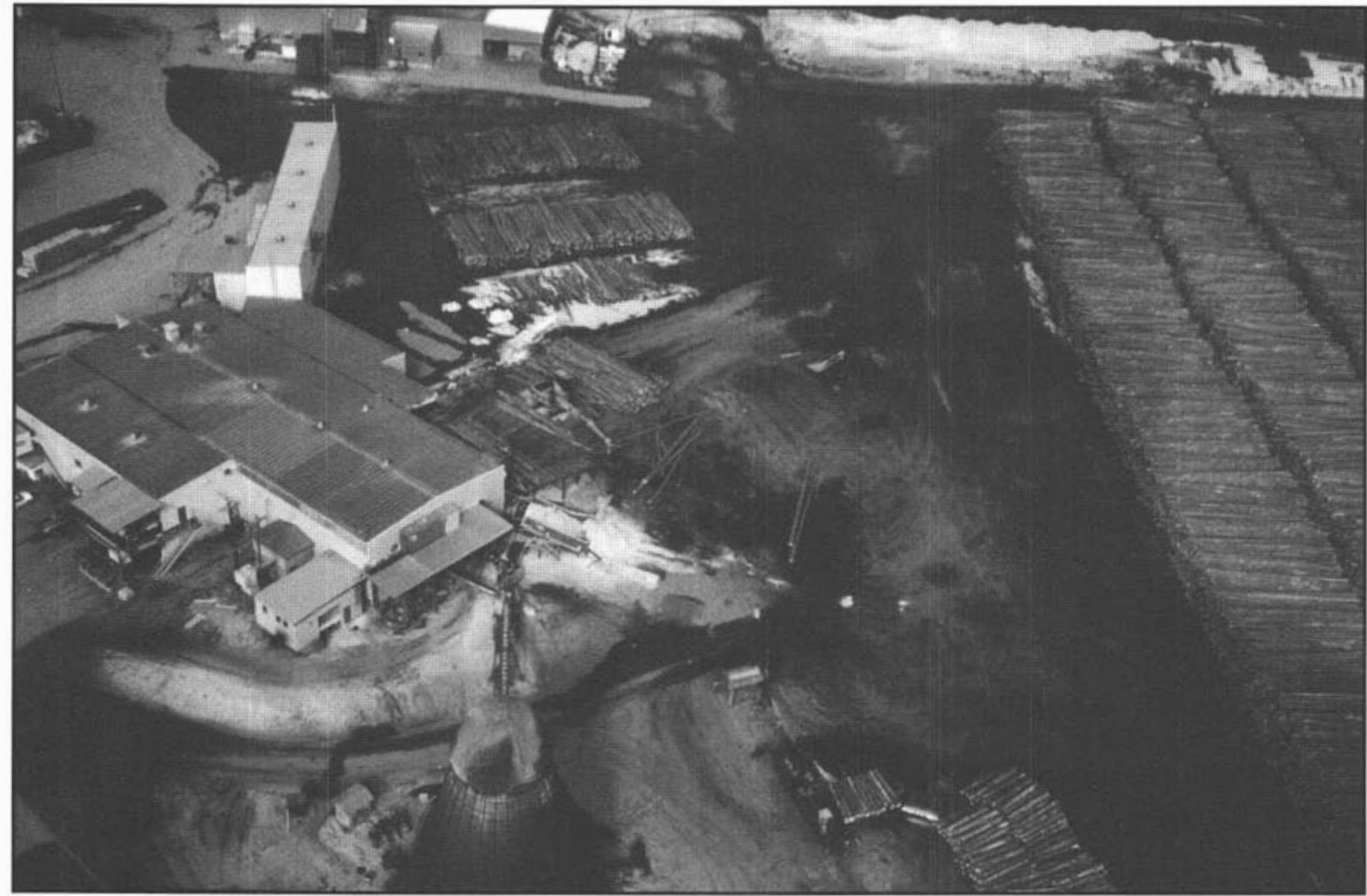

Fig. 5. The FAS undermines aboriginal views of the forest, one that emphasises tradition, a holistic view of the land, and sustainable community development. Tree Farm License 42, Tanizul Timber and Teeslee Forest Products were intended to fulfill this vision of aboriginal forestry by promoting job creation, environmental and cultural enhancement.

but that they strive to participate in resource management (Pape and Salter 1998). Sharing decision-making power and contributing their traditional knowledge and wisdom are important aspects of participation. Government, industry, and thirdparty interests must work with First Nations, rather than opposing or circumventing their concerns. Legally and constitutionally upheld rights give First Nations' groups considerable power to argue for the protection of their traditional lands, resource uses, and values in exclusionary forest management plans such as the FAS.

\section{Aboriginal Land Claims}

Ownership of virtually the entire province of $\mathrm{BC}$ is under dispute and has been for 120 years (Nathan 1993). Aboriginal people are seeking reunion with their traditional lands under land claim settlements and self-government agreements to achieve a stable economic base and greater self-reliance. Of 198 Bands in British Columbia, 126 have initiated Land Claims through the BC Treaty Commission process (Lee and Symington 1997). Potential Land Claims represent $110 \%$ of the traditional territory of First Nations (there are several areas of overlap); this amounts to approximately $90 \%$ of BC's geographical area (NAFA 1996). Land claims will expand the land base directly controlled by First Nations and provide cash compensation for loss of land and past damages. Land claims will also increase the role of First Nations in the use and management of traditional lands to which they have no title; for example, through formal representation on land-use planning, resource co-management, and environmental assessment boards. Until the questions of who has title to BC's land base and control over key areas of the forest sector are resolved, uncertainty will overshadow the management of provincial forests.
The BC Treaty Commission process creates a wide spectrum of potential consequences for government forest managers and the forest industry. Despite such doubt, the FAS requires no assurance of title to the land proposed for zoning nor raises questions concerning the potential impact of land claims on environmental protection, timber flow, forest management systems, economic certainty or employment stability.

\section{Resource and Sanctuary: Aboriginal Views of the Forest}

There is no single aboriginal view of the forest. BC's 198 bands and 180000 aboriginal people do not share the same histories, geographic realities, languages, cultural values, or attitudes (Nathan 1993). However, for many BC First Nations, the forest environment is synonymous with community and cultural survival. Extreme changes confront the province's 415 aboriginal settlements. Radical shifts in traditional ways of life have been prompted by displacement from traditional lands, loss of resource access and control, economic disruption, interference with traditional spiritual practices and educational processes (Sherry 1999). Despite these impacts, adaptability in the face of change is encouraging the survival of BC First Nations.

\section{Aboriginal Forest Values}

Forests are an essential part of First Nations' heritage and future. In a time of diminishing resources and increasingly entrenched interests, BC First Nations are endeavouring to become a presence in managing the extensive forests they inhabit. Many communities view the forest sector as "a way to break the shackles of a national system of forced welfare and dependency on the Indian Act" (Nathan 1993). According to the results of 
a 1990 study by the Intertribal Forestry Association of British Columbia, "aboriginal peoples see forestry as one of the main ways out of economic depression and as a vehicle for job creation, community stability, and environmental and cultural enhancement" (Bombay 1993). However, few First Nations are willing to participate in an industry dedicated to the status quo. Aboriginal leaders across the province emphasize their innovative goal of blending tradition, cultural wisdom, and a holistic view of the land to develop new ways of doing business in the forest that promotes sustainable community development and balanced use of resources (Kosek 1993). The FAS is insensitive to these aspirations, clashing with First Nations' needs and values related to forests.

The FAS would zone the forest into "a series of special-use areas corresponding to a range of forest values society demands" (Binkley 1997). However, this concept of public interests and public values does not embody aboriginal interests and values. The FAS undermines the aboriginal view of forests as home; as a spiritual, cultural, and economic base; a place of ancestral meaning; a locale for education and transmission of cultural skills; and a provider of food, medicine, and material needs (Sherry 1999). The strategy places the interests of the new dominant society above those of minority aboriginal groups, making "an ancient way of life subject to the apparent modern-day whims of an alien culture" (Erasmus 1989).

\section{Traditional Environmental Knowledge and Management Systems}

Despite the fact that the FAS aims to rebuild the relationship between humans and nature, no attempt is made to integrate the time-tested perceptions and approaches of aboriginal people into forest management. Instead, the emphasis is on "the wonderful creativity of science and technology" to "preserve the wild places foresters love" (Binkley 1997). Traditional environmental knowledge and management systems (TEKMS) are overlooked as valuable sources of environmental information and effective strategies for ensuring sustainable use of local natural resources (Johnson 1992, Berkes 1993, Johannes 1993). The application of TEKMS to forest management issues has the potential to overcome perceptual, cultural, and disciplinary barriers. For instance, the TEKMS of the Nuu-ChahNulth, the Nisga'a, the Gitxsan, and the Wet'suwet'en are recognized as complementary to scientific understanding and are being incorporated into improved, sustainable forest standards and practices (NAFA 1996).

\section{"We Are All Here To Stay"}

In the final analysis, zoning the land into intensive timber production areas, integrated management areas, and strictly protected areas would mean the imposition of rules and regulations that restrict or eliminate aboriginal use and stewardship of traditional lands (Bray and Irvine 1993). The FAS defies practical application. The conflicts related to its implementation are unimaginable. Were not the memories of Haida elders in button-blankets blockading Lyell Island logging roads; the Hiawatha occupation of Serpent Mounds Provincial Park; and the armed stand-offs by the Mohawk at Oka and the Chippewa at Ipperwash haunting enough images, poignant enough lessons? The FAS remains silent on aboriginal issues, perpetuating outdated standards of engagement and bygone paradigms of forest development. Forest management and planning, without complete consideration of aboriginal rights, land claims, environmental perspectives, forest values, and knowledge systems is doomed not only to failure, but to promoting continued acrimony and divisiveness between aboriginal and non-aboriginal people.

\section{Maintaining Forest Integrity through Multi- Resource Management}

While fraught with difficulties, elements of the FAS could be applied within an ecosystem approach to meet the economic needs of those who rely on the forest industry as well as meeting ecological and social objectives.

Retaining remnant late seral stage habitat patches, a diversity of stand ages and sizes, and landscape connectivity are essential for maintaining biodiversity. However, managing some portions of the landscape intensively and making greater investment in research and silviculture may reduce the need to exploit increasingly remote and economically unviable sites. The potential exists to reduce the total area used for timber production in BC and provide a more structurally diverse forest landscape to meet the habitat requirements of a variety of species. At the scale of individual watersheds, an ecosystem approach that incorporates the above aspects of the FAS would allow the flexibility to consider the unique geography and species composition of harvest areas as well as allow new information to be incorporated into future management decisions.

Faced with great opportunity to forge new alliances, the forest industry, government, and First Nations also might consider components of the FAS in determining how forest management and extraction will proceed. Without doubt, intensive forest management zones and strictly protected areas are incompatible with aboriginal ideas of multiple use forests areas that provide for cultural, educational, spiritual, and economic self-sufficiency. Alternatively, joint-use areas have the potential to make lands and resources accessible to select First Nations. These zones could be managed on an integrated basis through outright ownership, special long-term aboriginal tenures, resource-harvesting leases, advisory bodies, or co-operative/joint management agreements. These mechanisms offer possibilities for reconciling traditional and nontraditional values, goals, expectations, and economies, putting the community back into aboriginal forestry (Booth 1998).

\section{Conclusion}

Binkley (1997) promotes the FAS as a land management approach that will provide for the needs, values, and socioeconomic welfare of all British Columbians. However, to the sagacious reader, it quickly becomes apparent that the FAS does not recognize ecosystem processes nor honour aboriginal issues, but only considers the economically efficient allocation of land and resources. We have shown that assumption 2 and assumption 3 of the FAS are unlikely to be realistic. This simplification of $\mathrm{BC}$ forest management may show short-term profits in the ledger book, but will not achieve the desired improvements in wildlife conservation nor address considerations of aboriginal rights and title, community development, or cultural preservation. In contrast to the FAS, we argue there is a need to move away from the elusive goal of large-scale ecosystem manipulation towards an ideal of multi-resource forest management. To do this we will need to respect the interactions of the parts and processes, manage for multiplicity, and seek 
the production of several interdependent substances and services across the entire landscape.

\section{Acknowledgements}

We gratefully acknowledge the assistance of Rod Dieser, University of Alberta, during the development phases of this manuscript. We thank Dr. W. Kessler, University of Northern British Columbia, for stimulating us to evaluate the FAS from our disciplinary perspectives. Appreciation is also expressed to Dr. W. Kessler, Dr. S. McNay, R.P.F., Slocan Forest Products, and Sue Grainger, R.P.F., John Prince Research Forest, who offered valuable comment on drafts of this paper.

\section{References}

Bengston, D.N. 1994. Changing forest values and ecosystem management. Society and Natural Resources 7: 515-533.

Berkes, F. 1993. Traditional ecological knowledge in perspective. In J.T. Inglis (ed.). Concepts and Cases: Traditional Ecological Knowledge. pp. 1-10. IDRC, Ottawa, ON.

Binkley, C.S. 1997. Preserving nature through intensive plantation forestry: The case for forestland allocation with illustrations from British Columbia. For. Chron. 73: 553-559.

Bombay, H. 1993. Many things to many people: Aboriginal forestry in Canada is looking toward balanced solutions. Cultural Survival Quarterly 17: 15-18.

Booth, A. 1998. Putting "forestry" and "community" into First Nations' resource management. For. Chron. 74: 347-352.

Bray, D.B. and D. Irvine. 1993. Resource and sanctuary: Indigenous peoples, ancestral rights, and the forests of the Americas. Cultural Survival Quarterly 17: 12-14.

British Columbia Ministry of Forests. 1994. The economic impacts of timber harvesting in British Columbia. Ministry of Forests, Economics and Trade Branch. Victoria, BC.

British Columbia Ministry of Forests. 1995. Biodiversity guidebook - Forest practices code of British Columbia. BC Ministry of Forests, Victoria, BC

Bunnell, F.L. 1996. Toto, this isn't Kansas: Changes in integrated forest management. Integrated Forest Management Workshop. Location: http://mf.ncr.forestry.ca/conferences/ifm/bunnelleng.html. Site Visit: 15/09/98.

Burkey, T.V. 1989. Extinction in nature reserves: The effect of fragmentation and the importance of migration between reserve fragments. Oikos 55: 75-81.

Demarchi, M.W. and F.L. Bunnell. 1995. Forest cover selection and activity of cow moose in summer. Acta Theriologica 40: 23-36. Erasmus, G. 1989. A native viewpoint. In M. Hummel (ed.). Endangered Spaces: The Future for Canada's Wilderness. pp. 92-98. Key Porter Books, Toronto, ON.

Harris, L.D. 1984. The Fragmented Forest: Island Biogeography Theory and the Preservation of Biotic Diversity. University of Chicago Press, Chicago, IIl.

Harrison, S. and J. Voller. 1998. Connectivity. In J. Voller and S. Harrison (eds.). Conservation Biology Principles for Forested Landscapes. pp. 76-97. UBC Press, Vancouver, BC.

Huff, D.E., and J.D. Varley. 1999. Natural regulation in Yellowstone National Park's northern range. Ecological Applications 9: 17-29. Johannes, R.E. 1993. Integrating traditional ecological knowledge and management with environmental impact assessment. In J.T. Inglis (ed.). Concepts and Cases: Traditional Ecological Knowledge. pp. 33-40. IDRC, Ottawa, ON.

Johnson, M. 1992. LORE: Capturing Traditional Ecological Knowledge. Dene Cultural Institute, Hay River, NWT.

Kosek, J. 1993. Ethics, economics, and ecosystems: Can British Columbia's indigenous people blend the economic potential of forest resources with traditional philosophies? Cultural Survival Quarterly 17: 19-23.
Lee, C.A. and P. Symington. 1997. Land claims process and its potential impact on wood supply. Forestry Chronicle 73: 349-352.

MacKinnon, A. 1998. Biodiversity and old-growth forests. In J. Voller and S. Harrison (eds.). Conservation Biology Principles for Forested Landscapes. pp. 146-184. UBC Press, Vancouver, BC.

McFarlane, B.L., P.C. Boxall and W. Adamowicz. 1998. Big game hunters in Alberta: their activities, values, and preferences in relation to sustainable forest management. Working Paper 1998-4, Sustainable Forest Management Network, University of Alberta, Edmonton, $\mathrm{AB}$.

Nathan, H. 1993. Aboriginal forestry. In K. Drushka, B. Nixon and R. Travers (eds.). Touch Wood: BC Forests at the Crossroads. pp. 137-170. Harbour Publishing, Madeira Park, BC.

National Aboriginal Forestry Association (NAFA). 1996. Aboriginal forestry: significant developments and events 1992-1995. Location: http://sae/ca/nafa/forrep.htm. Site Visit: 15/02/99.

Newmark, W.D. 1985. Legal and biotic boundaries of western North American national parks: A problem of congruence. Biological Conservation 33: 197-208.

Nyberg, J.B. and D.W. Janz. 1990. Deer and elk habitats in coastal forests of southern Vancouver Island. Special Report Series No. 5. BC Ministry of Forests and BC Ministry of Environment, Victoria, BC. Pape and Salter. 1998. Delgamuukw: A summary of the Supreme Court of Canada decision. Unpublished Report, Law Firm of Pape and Salter, 460-220 Cambie Street, Vancouver, BC.

Reid, R. 1990. Update of the value of wildlife. Ministry of Environment, Lands, and Parks Memorandum, March 2, 1990. Ministry of Environment, Lands, and Parks Memorandum, Wildlife Branch, Victoria, $\mathrm{BC}$.

Reid, R. 1997. The economic value of resident hunting in British Columbia, 1995. BC Ministry of Environment, Lands and Parks, Wildlife Branch, Victoria, BC.

Schieck, J., M. Nietfeld and J.B. Stelfox. 1995. Differences in bird species richness and abundance among three successional stages of aspen-dominated boreal forests. Canadian Journal of Zoology 73: 1417-1431.

Seip, D.R. 1998. Ecosystem management and the conservation of caribou habitat in British Columbia. Rangifer Special Issue No. 10: 203-211. Shafer, C.L. 1990. Nature Reserves: Island Theory and Conservation Practice. Smithsonian Institution Press, Washington, D.C.

Sherry, E.E. 1999. Protected areas and aboriginal interests: At home in the Canadian Arctic wilderness. International Journal of Wilderness 5: 17-21.

Simberloff, D. 1998. Flagships, umbrellas, and keystones: is singlespecies management passé in the landscape era? Biological Conservation 3: 247-257.

Soulé, M.E. and D. Simberloff. 1986. What do genetics and ecology tell us about the design of nature reserves? Biological Conservation 35: 19-40.

Stone, M. 1988. Economic values and impacts of freshwater sport fishing in British Columbia. Ministry of Environment, Lands, and Parks, Fisheries Management Report No. 91. Victoria, BC.

Swanson, F.J. and J.F. Franklin. 1992. New forestry principles from ecosystem analysis of Pacific Northwest forests. Ecological Applications 2: 262-274.

Taylor, P.D., L. Fahrig, K. Henein and G. Merriam. 1993. Connectivity is a vital element of landscape structure. Oikos 68: 571-573. Tracy, C.R. and P.F. Brussard. 1994. Preserving biodiversity: Species in landscapes. Ecological Applications 4: 205-207.

United Nations, 1992. Report of the UN Conference on Environment and Development (Rio de Janeiro, 3-14 June, 1992). United Nations, New York, NY.

Walters, C.J. 1986. Adaptive management of renewable resources. McMillan Publishing Co., New York, NY.

Wilcove, D.S. and R.M. May. 1986. National park boundaries and ecological realities. Nature 324: 206-207.

Wright, R.G. 1999. Wildlife management in the national parks: questions in search of answers. Ecological Applications 9: 30-36. 